\title{
Association of digital cushion thickness with sole temperature measured with the use of infrared thermography
}

\author{
G. Oikonomou, ${ }^{\star}$ P. Trojacanec, ${ }^{*}$ E. K. Ganda, ${ }^{*}$ M. L. S. Bicalho, ${ }^{*}$ and R. C. Bicalho*1 \\ *Department of Population Medicine and Diagnostic Sciences, College of Veterinary Medicine, Cornell University, Ithaca, NY 14853 \\ †Department of Epidemiology and Population Health, School of Veterinary Science, University of Liverpool, Neston, Cheshire, CH64 7TE, \\ United Kingdom
}

\section{ABSTRACT}

The main objective of this study was to investigate the association between digital cushion thickness and sole temperature measured by infrared thermography. Data were collected from 216 lactating Holstein cows at 4 to $10 \mathrm{~d}$ in milk (DIM). Cows were locomotion scored and sole temperature was measured after claw trimming (a minimum delay of 3 min was allowed for the hoof to cool) using an infrared thermography camera. Temperature was measured at the typical ulcer site of the lateral digit of the left hind foot. Immediately after the thermographic image was obtained, the thickness of the digital cushion was measured by ultrasonography. Rumen fluid samples were collected with a stomach tube and sample $\mathrm{pH}$ was measured immediately after collection. Additionally, a blood sample was obtained and used for measurements of serum concentrations of $\beta$-hydroxybutyrate (BHBA), nonesterified fatty acids (NEFA), and haptoglobin. To evaluate the associations of digital cushion thickness with sole temperature, a linear regression model was built using the GLIMMIX procedure in SAS software (SAS Institute Inc., Cary, NC). Sole temperature was the response variable, and digital cushion thickness quartiles, locomotion score group, rumen fluid $\mathrm{pH}$, rumen fluid sample volume, environmental temperature, age in days, and serum levels of NEFA, BHBA, and haptoglobin were fitted in the model. Only significant variables were retained in the final model. Simple linear regression scatter plots were used to illustrate associations between sole temperature (measured by infrared thermography at the typical ulcer site) and environmental temperature and between NEFA and BHBA serum levels and haptoglobin. Oneway ANOVA was used to compare rumen fluid $\mathrm{pH}$ for different locomotion score groups and for different digital cushion quartiles. Results from the multivariable linear regression model showed that sole temperature increased as locomotion scores increased and decreased

Received September 27, 2013.

Accepted April 4, 2014.

${ }^{1}$ Corresponding author: rcb28@cornell.edu as digital cushion thickness increased. These results were adjusted for environmental temperature, which was significantly associated with sole temperature. Serum levels of NEFA, BHBA, and haptoglobin were not associated with sole temperature. However, significant correlations existed between serum levels of NEFA and haptoglobin and between serum levels of BHBA and haptoglobin. Rumen fluid $\mathrm{pH}$ was not associated with either locomotion score or digital cushion thickness. In conclusion, we show here that digital cushion thickness was associated with sole temperature in cows at 4 to 10 DIM.

Key words: digital cushion, thermography, lameness, inflammation

\section{INTRODUCTION}

Lameness is a significant financial and welfare issue with a high prevalence in herds throughout the world and debilitating effects (Cook, 2003; Espejo and Endres, 2007). Lame cows can experience discomfort and pain of long duration (Green et al., 2002). Lameness has been classified as the most representative animalbased indicator of compromised welfare in dairy cattle (Whay et al., 2003).

The digital cushion is a complex structure composed mostly of adipose tissue located underneath the distal phalanx; it plays an important function in dampening compression of the corium tissue beneath the cushion. The biomechanical importance of the digital cushion in alleviating compression under the tuberculum flexorum of the distal phalanx is well known (Logue et al., 2004; Räber et al., 2004, 2006). Lischer et al. (2002) reported that the digital cushion was thinner and contained less fat tissue in ulcerated claws compared with healthy controls. Our research group conducted an observational cross-sectional study to investigate the association between claw horn disruption lesions (CHDL) and the thickness of the digital cushion and reported that digital cushion thickness (DCT) was a strong predictor of lameness (Bicalho et al., 2009). A further prospective longitudinal cohort study investigated the association between the thickness of the digital cushion at drying- 
off and the probability of lameness in the subsequent lactation. Lower DCT at drying off was associated with increased incidence of sole ulcers and white line disease in the subsequent lactation (Machado et al., 2011).

Infrared thermography (IRT) is a noninvasive technique that measures thermal radiation from the surface of an object and displays the information as a thermogram (Eddy et al., 2001). The temperature of extremities and skin is mainly affected by the underlying blood flow and tissue metabolism rate (Berry et al., 2003). Therefore, changes in blood flow will alter the amount of radiated heat that can be identified by IRT and may relate to inflammation of tissues underlying that point or to changes in metabolic activity (Head and Dyson, 2001). In equine medicine, IRT has been extensively used in diagnosing foot and leg problems including laminitis, navicular disease, and abscesses (Eddy et al., 2001). In farm animals, IRT has been used for clinical and subclinical mastitis diagnosis (Berry et al., 2003; Colak et al., 2008; Polat et al., 2010), for detection of viral diarrhea or respiratory infections in calves (Schaefer et al., 2007, 2012), or for detection of cattle infected with foot-and-mouth disease (Rainwater-Lovett et al., 2009). Nikkhah et al. (2005) reported that IRT could detect elevated coronary band temperatures in cows with sole hemorrhage lesions, whereas Stokes et al. (2012) recently demonstrated that IRT was reliable in detecting elevated temperatures associated with foot lesions. Moreover, Alsaaod and Buscher (2012) investigated the potential role of using IRT to measure claw temperature as a means to detect lameness in dairy cattle, and Wilhem et al. (2012) investigated the temperature distribution upon the ground contact area of the claw in cows affected with sole hemorrhages.

Haptoglobin is an acute phase protein synthesized by hepatocytes. Elevated levels of serum haptoglobin can indicate tissue damage, inflammation, and infection (Murata et al., 2004; Lomborg et al., 2008). Smith et al. (2010) reported that lameness due to claw disorders can be associated with a systemic acute phase response and elevated serum haptoglobin in dairy cattle. Postcalving serum levels of NEFA and BHBA are well accepted as energy balance indicators; increased concentrations are associated with a state of negative energy balance and have been correlated with increased disease incidence or decreased reproductive performance (Ospina et al., 2013).

Our main hypothesis was that DCT is not only associated with CHDL but may be associated with earlier signs of inflammation of the corium; that is, with increased sole temperature. Therefore, in an effort to better elucidate the potential role of DCT in CHDL development and lameness, we studied associations between DCT and sole temperature measured by IRT.
Additionally, serum indicators of energy balance and inflammation as well as rumen fluid $\mathrm{pH}$ were investigated for associations with increased sole temperatures.

\section{MATERIALS AND METHODS}

\section{Experimental Design}

Data were collected from a large commercial dairy farm located in Cayuga County, New York State. This farm was selected because of its long-standing relationship with the Ambulatory and Production Medicine Clinic at Cornell University (Ithaca, NY). The farm milked 2,800 Holstein cows 3 times daily in a double 52-stall parallel milking parlor. Lactating cows were housed in 6-row freestall barns with concrete stalls covered with rubber mattresses and bedded with recycled composted manure solids. The pen alleys had grooved-concrete flooring and were cleaned by automatic scrapers; all walkways to and from the milking barn and holding pen were covered with rubber. Dry cows were housed in freestall barns and stalls were deep bedded with composted manure solids. Footbaths were located in the exit lanes of the milking parlor. The footbath consisted of a $5 \%$ formalin solution applied at least 4 times weekly according with prevalence of infectious diseases (digital dermatitis and foot rot) and labor schedule and availability. Lactating cows were fed a TMR consisting of approximately $55 \%$ forage (corn silage, alfalfa haylage, and wheat straw) and $45 \%$ concentrate (cornmeal, soybean meal, canola, cottonseed, and citrus pulp). All lactating cows were scheduled to receive routine hoof trimming twice yearly. A protocol created in Dairy Comp 305 (Valley Ag Software, Tulare, CA) prompted trimming for lactating cows. Furthermore, all cows received routine hoof trimming at dry off.

Data were collected from January to April 2013, and 216 lactating cows at 4 to 10 DIM were used. On the basis of a priori sample size calculations, it was estimated that a total sample size of 200 cows (approximately 50 cows per DCT quartile), considering an average sole temperature of 18 and a standard deviation of 5 , would permit detection of differences in sole temperature of $\geq 2.8$ between any given DCT quartile group. Sample size calculations were based on an $\alpha$ value of 0.05 , confidence of 0.80 , and a 2 -tailed $t$-test.

The cows were restrained for hoof trimming with a standing chute HSeries (Comfort HoofCare, Baraboo, WI). Before cows entered the trimming chute, a member of the research team recorded their locomotion score on a scale from 1 to 5 , with 1 being the most desirable score (Sprecher et al., 1997; Bicalho et al., 2007). The system used was a 5 -point scale, where $1=$ normal, 2 
$=$ presence of a slightly asymmetric gait, $3=$ the cow clearly favored one or more limbs (moderately lame), 4 $=$ severely lame, to $5=$ extremely lame (non-weightbearing lame). After the hind left foot was trimmed, it was cleaned with a paper towel and left hanging for 3 min. Subsequently, its sole temperature was measured with the use of IRT and a handheld portable infrared camera (E30 Box, FLIR Systems, Wilsonville, OR). Temperature was measured at the typical ulcer site (as defined by Toussaint Raven, 1989; Figure 1). All animals were examined at the same physical facilities and at a similar time of the day as environmental temperature was recorded. The camera was always held $2 \mathrm{~m}$ away from the sole and at the same angle. The emissivity value was set to 0.95 . The FLIR Systems cameras are designed and factory calibrated for accurate temperature measurements and thermal imaging. The camera used in this study was new and therefore recently calibrated.

Immediately after the thermographic image was obtained, cows underwent digital sonographic B-mode examination with an Ibex ultrasound machine (Ibex Pro, E. I. Medical Imaging, Loveland, CO) equipped with a curved array probe set at $7.5 \mathrm{MHz}$, as previously described (Bicalho et al. 2009). The examination was always completed at the typical sole ulcer site assessing the distance from the inner margin of the sole (identified as a thin echogenic line) to the distal edge of the tuberculum flexorum of the third phalanx (identified as a thick echogenic line). The anatomical area of the digital cushion targeted for ultrasonography was the middle pad (Räber et al., 2004). Before the beginning of the Bicalho et al. (2009) study, the

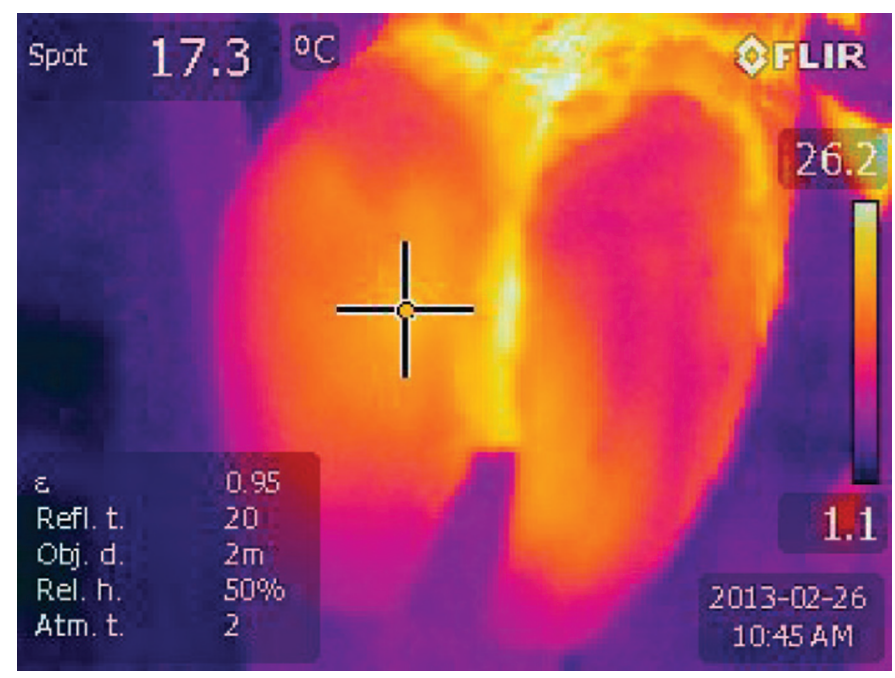

Figure 1. Infrared image of the left hind foot obtained 3 min after claw trimming. Color version available in the online PDF. ultrasound technique was evaluated in a pilot study (using 20 digits from cadaver feet) that assessed the association of ultrasound measurement and the actual measurement of the middle digital cushion pad after dissection of hooves. The ultrasound measurements of the middle digital cushion pad were not significantly different from the actual measurements of the dissected slaughterhouse specimens. The ultrasound machine settings (i.e., depth, echo-amplification, persistence, preand postprocessing) were kept constant throughout the study. Measurements were made in 1-mm increments.

Rumen fluid samples were collected with a stomach tube (described by Geishauser et al., 2012) adjusted to a fluid pump. The first $100 \mathrm{~mL}$ of obtained fluid was discarded to minimize the chances of saliva contamination. Immediately after sampling, rumen sample volume was recorded and $\mathrm{pH}$ was measured with the use of a calibrated Hanna combo portable electronic $\mathrm{pH}$ meter (Hanna Instruments, Woonsocket, RI).

Factors such as calving date and age in days at observation were obtained from the farm's database in Dairy Comp 305 (Valley Agricultural Software). Serum concentrations of NEFA were analyzed by enzymatic analysis (NEFA-C kit; Wako Pure Chemical Industries, Osaka, Japan). All spectrophotometric measurements were conducted using a microplate reader (BioTek Instruments, Winooski, VT). Serum samples were also tested for BHBA concentrations using an electronic BHBA measuring system (Precision Xtra, Abbott, Abingdon, UK) already validated for animal use. Precision Xtra was recently validated for use with stored bovine serum samples (Gordon et al., 2013). The system consists of a handheld meter and electrochemical test strips. After the test strip was inserted into the meter, serum was applied to the sample chamber. $\beta$-Hydroxybutyric acid in the sample is oxidized to acetoacetate in the presence of hydroxybuturate dehydrogenase with the concomitant reduction of $\mathrm{NAD}^{+}$to NADH. The NADH is reoxidized to $\mathrm{NAD}^{+}$by a redox mediator. After $10 \mathrm{~s}$, the concentration of BHBA $(\mathrm{mmol} / \mathrm{L})$ is displayed on the meter.

Haptoglobin concentration was determined using a colorimetric procedure that measures haptoglobinhemoglobin complex by estimated differences in peroxidase activity. The method was previously described and validated by Cooke and Arthington (2013). Briefly, $5 \mu \mathrm{L}$ of plasma or distilled water (for blank determination) was added to $7.5 \mathrm{~mL}$ of $o$-dianisidine solution $(0.6 \mathrm{~g} / \mathrm{L}$ of $o$-dianisidine, $0.5 \mathrm{~g} / \mathrm{L}$ of EDTA and 13.8 $\mathrm{g} / \mathrm{L}$ of sodium phosphate monobasic in distilled water; $\mathrm{pH}$ adjusted to 4.1) in a borosilicate tube. Twenty-five microliters of a hemoglobin solution $(0.3 \mathrm{~g} / \mathrm{L}$ of bovine hemoglobin in distilled water) was immediately added to each tube. All tubes were incubated in a water bath 
set at $37^{\circ} \mathrm{C}$ for $45 \mathrm{~min}$. After incubation, $100 \mu \mathrm{L}$ of a freshly prepared working concentration of $156 \mathrm{mM}$ hydrogen peroxide solution was added to each tube. All tubes were incubated for $1 \mathrm{~h}$ at room temperature. After incubation, $200 \mu \mathrm{L}$ of each tube was transferred into one well in a 96-well polystyrene flat-bottomed microplate, and optical density (OD) was immediately read at $450 \mathrm{~nm}$ in a microplate reader (model EL 340, BioTek Instruments). The OD from the blank sample was subtracted from the OD of all plasma-containing samples. Results were reported as OD readings at 450 $\mathrm{nm}$ wavelength, given that the method used does not contain a standard curve. The absolute absorbance values were used for the statistical analysis.

\section{Statistical Analysis}

To facilitate data analysis and interpretation of results, the following variables were categorized: DCT [4 quartiles, 1 for cows categorized in the lowest and 4 for cows categorized in the highest quartile; MedCalc, version 10.4.0.0 (MedCalc Software, Mariakerke, Belgium) was used to categorize cows into terciles] and locomotion score $(1=$ sound, locomotion scores 1 and $2 ; 2=$ mildly lame, locomotion score 3 , and $3=$ severely lame, locomotion scores 4 and 5).

To evaluate the associations of DCT with sole temperature, a linear regression model was built using the GLIMMIX procedure in SAS (SAS Institute Inc., Cary, $\mathrm{NC}$ ). Sole temperature was the response variable and the following variables were fitted in the model: DCT quartile, locomotion score group, rumen fluid $\mathrm{pH}$, rumen fluid sample volume, environmental temperature, age in days, and serum levels of NEFA, BHBA, and haptoglobin. A backward stepwise elimination process was followed until only variables with a $P$-value $<0.1$ were retained in the final model. Statistical significance was declared at $P<0.05$. The Akaike's information criterion (AIC) was used to evaluate goodness of fit. Interactions between the variables finally retained in the model were tested but not retained in the final model because none was found to be significant. Digital cush- ion thickness was also fitted as a continuous variable in the same final model, as well as a binary variable (low and high DCT).

Simple linear regression scatter plots were used to illustrate associations between sole temperature and environmental temperature and between NEFA or BHBA serum levels and haptoglobin. One-way ANOVA was used to compare rumen fluid $\mathrm{pH}$ for different locomotion score groups and for different DCT quartiles.

\section{RESULTS}

Descriptive statistics of the studied traits are presented in Table 1. In Table 2, we show DCT mean and standard deviation for each DCT quartile. Variables retained in the linear regression model that evaluated the associations between DCT and sole temperature were DCT quartiles $(P=0.002)$, locomotion score groups $(P=0.003)$, and environmental temperature $(P<0.0001)$. In Table 3 , we show sole temperatures differences (with $P$-values) between different DCT quartiles, between high and low DCT (result obtained from running the same model with DCT treated as a binary trait), and between different locomotion score groups. The adjusted difference between sole temperatures of cows in the lowest DCT quartiles and cows in the highest quartile was $2.96^{\circ} \mathrm{C}$. The adjusted difference between sole temperatures of sound cows and severely lame cows was $2.54^{\circ} \mathrm{C}$. Differences are adjusted for multiple comparisons (Tukey-Kramer adjustment). Sole temperature was significantly associated with environmental temperature $(P<0.0001)$. Adjusted sole temperatures for different DCT quartiles and different locomotion score groups are presented in Figure 2. Similar results were obtained when DCT was fitted in the model as a continuous variable. Digital cushion thickness (adjusted again for locomotion score and environmental temperature) was negatively associated with sole temperature $(P<0.001)$.

In Figure 3, we show a simple linear regression scatter plot indicating the positive association between

Table 1. Descriptive statistics of the studied traits

\begin{tabular}{lcrrrr}
\hline Trait & No. of cows & \multicolumn{1}{c}{ Mean } & SD & Minimum & Maximum \\
\hline Digital cushion thickness $(\mathrm{mm})$ & 214 & 9.71 & 1.91 & 5.00 & 16.00 \\
Environmental temperature $\left({ }^{\circ} \mathrm{C}\right)$ & 216 & 4.35 & 3.09 & -3.33 & 10.00 \\
NEFA (mmol/L) & 211 & 0.86 & 0.33 & 0.20 & 2.00 \\
BHBA (mmol/L) & 211 & 0.92 & 0.51 & 0.20 & 3.30 \\
Locomotion score & 216 & 1.91 & 0.89 & 1.00 & 4.00 \\
Haptoglobin (optical density) & 211 & 0.19 & 0.05 & 0.12 & 0.43 \\
Sole temperature $\left({ }^{\circ} \mathrm{C}\right)$ & 215 & 17.26 & 4.70 & 3.90 & 26.00 \\
pH & 201 & 6.83 & 0.39 & 5.85 & 8.44 \\
Age $(\mathrm{d})$ & 216 & $1,268.00$ & 439.14 & 719.00 & $2,637.00$ \\
\hline
\end{tabular}


a.

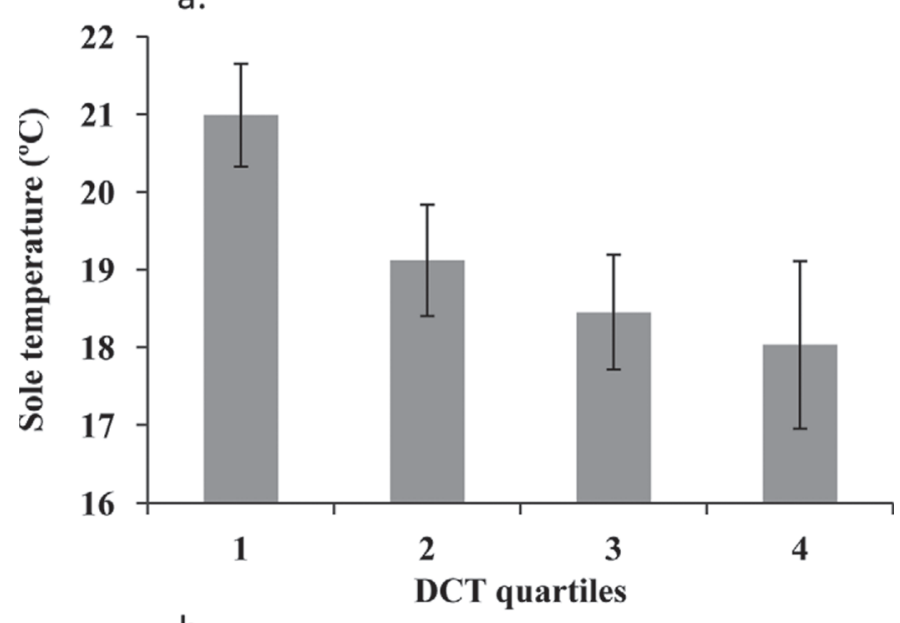

b.

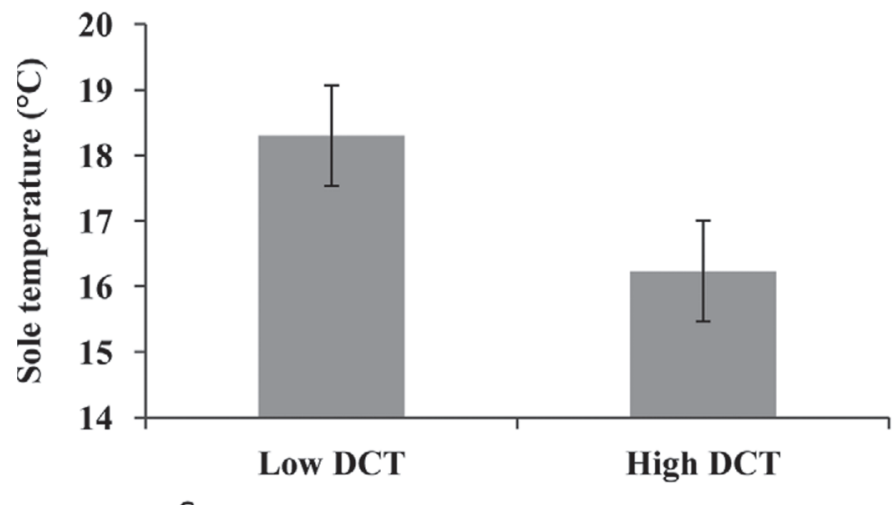

C.

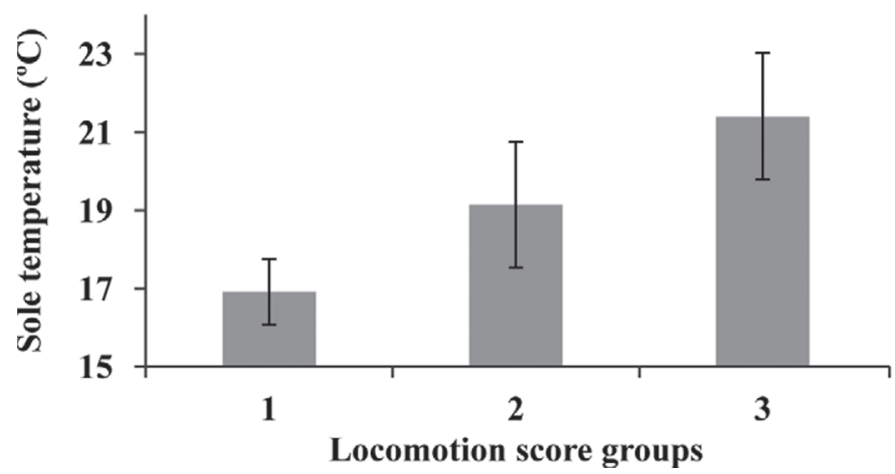

Figure 2. Adjusted sole temperature (with 95\% CI) for different digital cushion thickness (DCT) quartiles (a) or for low and high digital cushion thickness (b) and for different locomotion score groups (c; $1=$ sound, $2=$ mildly lame, $3=$ severely lame).

sole temperature measured by IRT and environmental temperature $\left(\mathrm{R}^{2}=0.48, P<0.0001\right)$.

Serum levels of NEFA, BHBA, and haptoglobin were not associated with sole temperature. However, significant correlations existed between serum levels of NEFA and haptoglobin and between serum levels of BHBA and haptoglobin. A simple linear regression scatter plot indicating the positive association of serum
Table 2. Mean and standard deviation for each digital cushion thickness (DCT) quartile

\begin{tabular}{lcrc}
\hline $\begin{array}{l}\text { DCT } \\
\text { quartile }\end{array}$ & $\begin{array}{c}\text { No. of } \\
\text { cows }\end{array}$ & $\begin{array}{c}\text { Mean } \\
(\mathrm{mm})\end{array}$ & $\mathrm{SD}$ \\
\hline 1 & 58 & 7.60 & 0.75 \\
2 & 54 & 9.00 & 0.00 \\
3 & 65 & 10.40 & 0.49 \\
4 & 37 & 12.85 & 1.15 \\
\hline
\end{tabular}

level of NEFA and serum levels of haptoglobin $\left(\mathrm{R}^{2}=\right.$ $0.13, P=0.05)$ and a simple linear regression scatter plot indicating the positive association of serum level of NEFA and serum levels of haptoglobin $\left(\mathrm{R}^{2}=0.31, P<\right.$ 0.0001) are presented in Figure 4.

Rumen fluid $\mathrm{pH}$ was not associated with either locomotion score or DCT (Table 4).

\section{DISCUSSION}

Sole temperature measured by IRT was, in the present study, strongly and positively associated with locomotion score in the immediate postpartum period. It should be noted that our study was a cross-sectional one, conducted in a single herd, and therefore the presented results should be treated with caution. Further longitudinal studies using multiple herds are needed to validate the methods used and the findings. Nikkhah et al. (2005) reported an increased prevalence of sole hemorrhages coinciding with increased temperatures of the coronary band (measured by IRT). Similarly, Stokes et al. (2012) recently reported that IRT was reliable in detecting elevated temperatures associated with foot

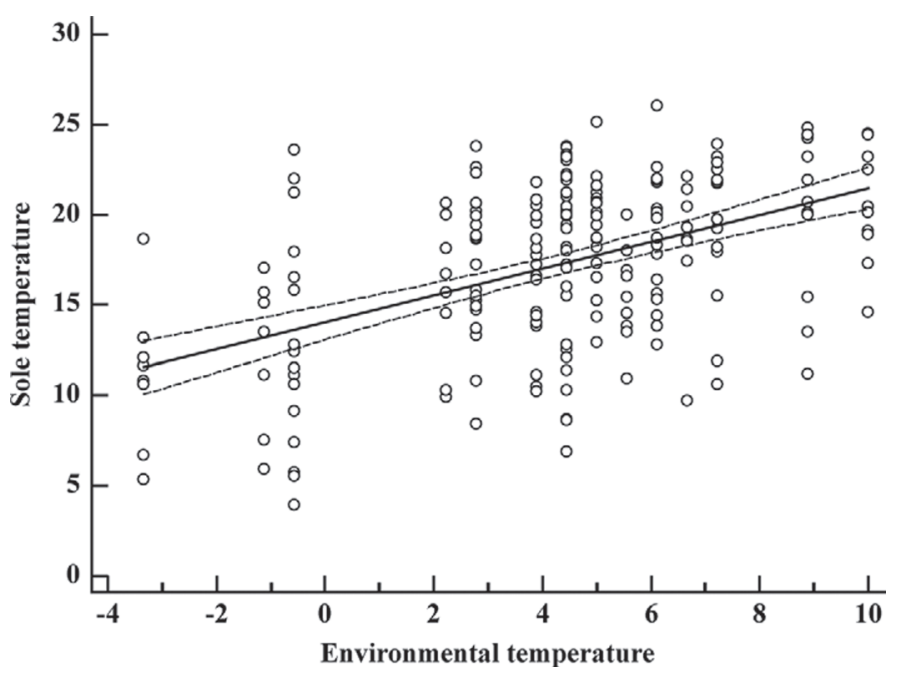

Figure 3. Simple linear regression scatter plot indicating the positive association of sole temperature measured by infrared thermography $(\mathrm{IRT})$ and environmental temperature $\left(\mathrm{R}^{2}=0.48, P<0.0001\right)$. 
a)

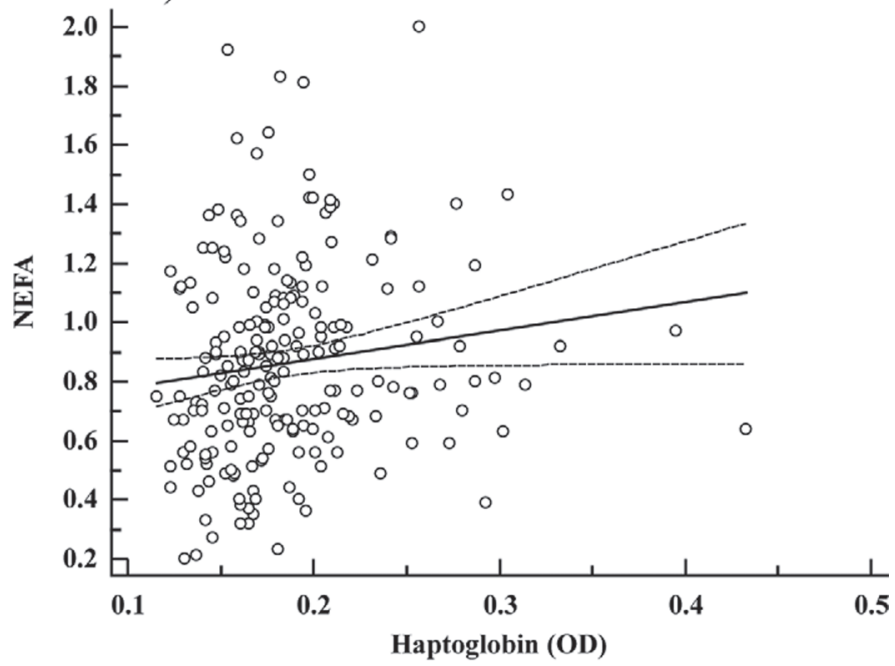

b)

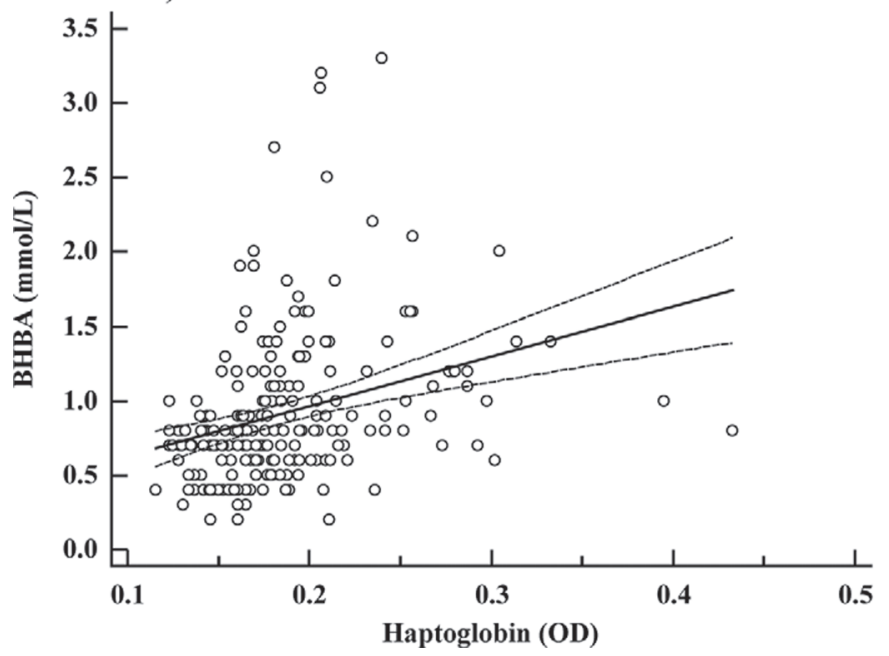

Figure 4. Simple linear regression scatter plot indicating the positive association of (a) serum level of NEFA and serum levels of haptoglobin $\left(\mathrm{R}^{2}=0.13, P=0.05\right)$, and (b) serum level of BHBA and serum levels of haptoglobin $\left(\mathrm{R}^{2}=0.31, P<0.0001\right)$. $\mathrm{OD}=$ optical density.

lesions. Alsaaod and Buscher (2012) also demonstrated that the temperature of the coronary band, measured again with the use of IRT, was significantly increased in cows with foot lesions compared with cows without foot lesions. In the Wilhem et al. (2012) study, the temperature distribution upon the ground contact area of the claw was consistent with the distribution pattern of sole hemorrhages. Recently, Alsaaod et al. (2014) showed that IRT is a promising diagnostic tool in screening for the presence of digital dermatitis in dairy cows. A possible explanation for these findings is that inflammation of the corium and the accompanying increased blood flow and tissue metabolism rate associated with lameness and foot lesions lead to increased
Table 3. Adjusted sole temperature differences (Adj. diff. \pm SE) and $P$-values between different digital cushion thickness (DCT) quartiles and different locomotion score groups ${ }^{1}$

\begin{tabular}{lcl}
\hline Variable & Adj. diff. $\pm \mathrm{SE}$ & $P$-value \\
\hline DCT quartile comparison & & \\
1 vs. 2 & $1.87 \pm 0.75$ & 0.06 \\
1 vs. 3 & $2.54 \pm 0.73$ & 0.003 \\
1 vs. 4 & $2.96 \pm 1.05$ & 0.03 \\
2 vs. 3 & $0.67 \pm 0.74$ & 0.80 \\
2 vs. 4 & $1.09 \pm 1.07$ & 0.74 \\
3 vs. 4 & $0.42 \pm 1.01$ & 0.98 \\
Locomotion score groups & & \\
1 vs. 2 & $-2.24 \pm 0.85$ & 0.02 \\
1 vs. 3 & $-4.50 \pm 1.61$ & 0.02 \\
2 vs. 3 & $-2.26 \pm 1.62$ & 0.34 \\
\hline
\end{tabular}

${ }^{1}$ The differences are adjusted for multiple comparisons (Tukey-Kramer adjustment).

radiated heat that can be detected by IRT (Head and Dyson, 2001; Berry et al., 2003).

Additionally, and to the best of our knowledge, this is the first study that shows a significant association between DCT and sole temperature. The digital cushion serves as a shock absorber between the sharp edge of the tuberculum flexorum of the third phalanx and the corium, and digital cushion biomechanical importance is well described (Logue et al., 2004; Räber et al. 2006). Our research group has already shown that DCT is a strong predictor of lameness and highly associated with CHDL (Bicalho et al., 2009; Machado et al., 2011). We have also recently shown that part of this relationship is heritable and therefore it could be manipulated through genetic selection (Oikonomou et al., 2014). The results of the present study provide new information regarding the role of the digital cushion because we show here that DCT is associated with sole temperature. Decreased DCT in the present study was associated with increased sole temperature.

Bicalho et al. (2009) hypothesized that the decrease in DCT observed during the first months of lactation is associated with primary damage to the corium, which

Table 4. Multiple comparisons of rumen $\mathrm{pH}$ means (with 95\% CI) for different digital cushion thickness (DCT) quartiles and different locomotion score groups $(1=$ sound, $2=$ mildly lame, $3=$ severely lame)

\begin{tabular}{lccc}
\hline Item & $\begin{array}{c}\text { No. of } \\
\text { cows }\end{array}$ & $\begin{array}{c}\text { Mean ruminal } \\
\text { fluid pH }\end{array}$ & $95 \%$ CI \\
\hline DCT quartile & & & \\
1 & 55 & 6.81 & $6.71-6.92$ \\
2 & 53 & 6.84 & $6.73-6.95$ \\
3 & 63 & 6.80 & $6.70-6.89$ \\
4 & 30 & 6.89 & $6.75-7.03$ \\
Locomotion score group & & & \\
1 & 154 & 6.83 & $6.76-6.89$ \\
2 & 37 & 6.81 & $6.68-6.93$ \\
3 & 10 & 6.92 & $6.67-7.16$ \\
\hline
\end{tabular}


may aggravate and eventually lead to CHDL. Results presented here may support this hypothesis. Reduced DCT was associated with early signs of inflammation (assuming that corium inflammation is a possible explanation for the observed increased sole temperature) in the beginning of lactation and before the development of visible claw lesions. It is important to note here that the associations described above are corrected for environmental temperature, which was found to be linearly associated with IRT-measured sole temperature $\left(\mathrm{R}^{2}=0.48, P<0.0001\right)$. The fact that environmental temperature significantly affects IRT temperature measurements is already well known and described in the literature (Eddy et al., 2001; Alsaaod and Buscher, 2012; Stokes et al., 2012).

On the other hand, rumen fluid $\mathrm{pH}$ was not found to be associated with increased sole temperature or increased locomotion scores. Low rumen $\mathrm{pH}$ has long been associated with ruminal acidosis and lameness (Nocek, 1997). Studies associating rumen pH measurements with lameness are scarce, however. It has been shown that high-concentrate diets can be associated with increased lameness incidence (Manson and Leaver, 1988). However, several studies have failed to associate high-starch diets with the development of claw lesions (Bergsten and Frank, 1996; Livesey et al., 2003; Offer et al., 2004). Bramley et al. (2013) recently showed that "acidotic" herds were more likely to have increased locomotion scores. However, they used herd as their studied unit and therefore their results are not directly comparable to results presented here. Admittedly, our study is a cross-sectional observational one and the lack of an association between rumen $\mathrm{pH}$ and locomotion scores could be due to the fact that cows experiencing SARA may develop claw lesions months later. Although the incidence of SARA is higher during the first month of lactation (Nocek, 1997), 4 to 10 DIM may still be too soon for its development (Geishauser et al., 2012). The method we used for $\mathrm{pH}$ measurements has recently been used in a large-scale study by Geishauser et al. (2012). We discarded the first $100 \mathrm{~mL}$ of rumen fluid to avoid possible saliva contamination of our samples but a risk of saliva contamination may still exist. On the other hand, rumenocentesis was not an option for us because the study was conducted in a commercial herd that would not consent to rumenocentesis, especially because we were planning to enroll over 200 animals. Studies have shown potential complications of this approach, such as fever, abscesses, and adhesions, which could lead to premature culling (Strabel et al., 2007).

Crawford et al. (2005) reported increased serum levels of haptoglobin around parturition and speculated that this might be due to negative energy balance. Hiss et al. (2009) reported higher serum haptoglobin levels in cows with high levels of BHBA and NEFA during the peripartum period. This is also confirmed by our findings because serum concentrations of NEFA and BHBA in this study were linearly associated with serum concentrations of haptoglobin. Higher postpartum NEFA and BHBA levels are known to be associated with compromised immune functions and inflammation (Lacetera et al., 2004; Hammon et al., 2006). Although lameness and claw lesions have been associated with increased haptoglobin levels (Smith et al., 2010), serum concentrations of haptoglobin were not associated here with increased sole temperature. A possible explanation for this observation may be that parturition alone can cause increased haptoglobin levels, even in healthy cows (Humblet et al., 2006). Additionally, haptoglobin concentrations are elevated in fresh cows suffering from metritis (Huzzey et al., 2009). Given that our observations occurred 4 to $10 \mathrm{~d}$ after calving, these effects may have masked possible associations between sole temperature and haptoglobin.

\section{CONCLUSIONS}

The main finding of the present study was that decreased DCT was associated with increased sole temperature as measured by IRT.

\section{ACKNOWLEDGMENTS}

Funding was provided for research and publication by the USDA National Institute of Food and Agriculture (Washington, DC) Federal Formula Funds project NYC-478438.

\section{REFERENCES}

Alsaaod, M., and W. Buscher. 2012. Detection of hoof lesions using digital infrared thermography in dairy cows. J. Dairy Sci. 95:735742 .

Alsaaod, M., C. Syring, J. Dietrich, M. G. Doherr, T. Gujan, and A. Steiner. 2014. A field trial of infrared thermography as a noninvasive diagnostic tool for early detection of digital dermatitis in dairy cows. Vet. J. 199:281-285. http://dx.doi.org/10.1016/j. tvjl.2013.11.028.

Bergsten, C., and B. Frank. 1996. Sole haemorrhages in tied heifers in early gestation as an indicator of laminitis: Effects of diet and flooring. Acta Vet. Scand. 37:375-381.

Berry, R. J., A. D. Kennedy, S. L. Scott, B. L. Kyle, and A. L. Schaefer. 2003. Daily variation in the udder surface temperature of dairy cows measured by infrared thermography: Potential for mastitis detection. Can. J. Anim. Sci. 83:687-693.

Bicalho, R. C., V. S. Machado, and L. S. Caixeta. 2009. Lameness in dairy cattle: A debilitating disease or a disease of debilitated cattle? A cross-sectional study of lameness prevalence and thickness of the digital cushion. J. Dairy Sci. 92:3175-3184.

Bicalho, R. C., F. Vokey, H. N. Erb, and C. L. Guard. 2007. Visual locomotion scoring in the first seventy days in milk: Impact on pregnancy and survival. J. Dairy Sci. 90:4586-4591.

Bramley, E., N. D. Costa, W. J. Fulkerson, and I. J. Lean. 2013. Associations between body condition, rumen fill, diarrhoea and lame- 
ness and ruminal acidosis in Australian dairy herds. N. Z. Vet. J. 61:323-329. http://dx.doi.org/10.1080/00480169.2013.806882.

Colak, A., B. Polat, Z. Okumus, M. Kaya, L. E. Yanmaz, and A. Hayirli. 2008. Short communication: Early detection of mastitis using infrared thermography in dairy cows. J. Dairy Sci. 91:4244-4248.

Cook, N. B. 2003. Prevalence of lameness among dairy cattle in Wisconsin as a function of housing type and stall surface. J. Am. Vet. Med. Assoc. 223:1324-1328.

Cooke, R. F., and J. D. Arthington. 2013. Concentrations of haptoglobin in bovine plasma determined by ELISA or a colorimetric method based on peroxidase activity. J. Anim. Physiol. Anim. Nutr. (Berl.) 97:531-536.

Crawford, R. G., K. E. Leslie, R. Bagg, C. P. Dick, and T. F. Duffield. 2005. The impact of controlled release capsules of monensin on postcalving haptoglobin concentrations in dairy cattle. Can. J. Vet. Res. 69:208-214.

Eddy, A. L., L. M. Van Hoogmoed, and J. R. Snyder. 2001. The role of thermography in the management of equine lameness. Vet. J. 162:172-181.

Espejo, L. A., and M. I. Endres. 2007. Herd-level risk factors for lameness in high-producing Holstein cows housed in freestall barns. J. Dairy Sci. 90:306-314.

Geishauser, T., N. Linhart, A. Neidl, and A. Reimann. 2012. Factors associated with ruminal $\mathrm{pH}$ at herd level. J. Dairy Sci. 95:45564567.

Gordon, J. L., S. J. LeBlanc, and T. F. Duffield. 2013. Evaluation of accuracy of an electronic $\beta$-hydroxybutyrate meter using fresh and stored whole blood and serum from dairy cows. J. Dairy Sci. 96(E-Suppl. 1):55-56. (Abstr.)

Green, L. E., V. J. Hedges, Y. H. Schukken, R. W. Blowey, and A. J. Packington. 2002. The impact of clinical lameness on the milk yield of dairy cows. J. Dairy Sci. 85:2250-2256.

Hammon, D. S., I. M. Evjen, T. R. Dhiman, J. P. Goff, and J. L. Walters. 2006. Neutrophil function and energy status in Holstein cows with uterine health disorders. Vet. Immunol. Immunopathol. 113:21-29.

Head, M. J., and S. Dyson. 2001. Talking the temperature of equine thermography. Vet. J. 162:166-167.

Hiss, S., C. Weinkauf, S. Hachenberg, and H. Sauerwein. 2009. Short communication: Relationship between metabolic status and the milk concentrations of haptoglobin and lactoferrin in dairy cows during early lactation. J. Dairy Sci. 92:4439-4443.

Humblet, M. F., H. Guyot, B. Boudry, F. Mbayahi, C. Hanzen, F. Rollin, and J. M. Godeau. 2006. Relationship between haptoglobin, serum amyloid $\mathrm{A}$, and clinical status in a survey of dairy herds during a 6-month period. Vet. Clin. Pathol. 35:188-193.

Huzzey, J. M., T. F. Duffield, S. J. LeBlanc, D. M. Veira, D. M. Weary, and M. A. von Keyserlingk. 2009. Short communication: Haptoglobin as an early indicator of metritis. J. Dairy Sci. 92:621-625.

Lacetera, N., D. Scalia, O. Franci, U. Bernabucci, B. Ronchi, and A. Nardone. 2004. Short communication: Effects of nonesterified fatty acids on lymphocyte function in dairy heifers. J. Dairy Sci. 87:1012-1014.

Lischer, C. J., P. Ossent, M. Raber, and H. Geyer. 2002. Suspensory structures and supporting tissues of the third phalanx of cows and their relevance to the development of typical sole ulcers (Rusterholz ulcers). Vet. Rec. 151:694-698.

Livesey, C. T., J. A. Metcalf, and R. A. Laven. 2003. Effect of concentrate composition and cubicle bedding on the development of hoof haemorrhages in Holstein heifers after calving. Vet. Rec. 152:735-739.

Logue, D. N., J. E. Offer, and R. D. McGovern. 2004. The bovine digital cushion-How crucial is it to contusions on the bearing surface of the claw of the cow? Vet. J. 167:220-221.

Lomborg, S. R., L. R. Nielsen, P. M. Heegaard, and S. Jacobsen. 2008. Acute phase proteins in cattle after exposure to complex stress. Vet. Res. Commun. 32:575-582.

Machado, V. S., L. S. Caixeta, and R. C. Bicalho. 2011. Use of data collected at cessation of lactation to predict incidence of sole ulcers and white line disease during the subsequent lactation in dairy cows. Am. J. Vet. Res. 72:1338-1343.
Manson, F. J., and J. D. Leaver. 1988. The influence of concentrate amount on locomotion and clinical lameness in dairy cattle. Anim. Prod. 47:185-190.

Murata, H., N. Shimada, and M. Yoshioka. 2004. Current research on acute phase proteins in veterinary diagnosis: An overview. Vet. J. $168: 28-40$.

Nikkhah, A., J. C. Plaizier, M. S. Einarson, R. J. Berry, S. L. Scott, and A. D. Kennedy. 2005. Short communication: Infrared thermography and visual examination of hooves of dairy cows in two stages of lactation. J. Dairy Sci. 88:2749-2753.

Nocek, J. E. 1997. Bovine acidosis: Implications on laminitis. J. Dairy Sci. 80:1005-1028.

Offer, J. E., D. N. Logue, N. W. Offer, and M. Marsden. 2004. The effect of concentrate composition on lameness and hoof health in dairy cows. Vet. J. 167:111-113.

Oikonomou, G., G. Banos, V. Machado, L. Caixeta, and R. C. Bicalho. 2014. Short communication: Genetic characterization of digital cushion thickness. J. Dairy Sci. 97:532-536. http://dx.doi. org/10.3168/jds.2013-7212.

Ospina, P. A., J. A. McArt, T. R. Overton, T. Stokol, and D. V. Nydam. 2013. Using nonesterified fatty acids and beta-hydroxybutyrate concentrations during the transition period for herd-level monitoring of increased risk of disease and decreased reproductive and milking performance. Vet. Clin. North Am. Food Anim. Pract. 29:387-412.

Polat, B., A. Colak, M. Cengiz, L. E. Yanmaz, H. Oral, A. Bastan, S. Kaya, and A. Hayirli. 2010. Sensitivity and specificity of infrared thermography in detection of subclinical mastitis in dairy cows. J. Dairy Sci. 93:3525-3532.

Räber, M., C. Lischer, H. Geyer, and P. Ossent. 2004. The bovine digital cushion-A descriptive anatomical study. Vet. J. 167:258-264.

Räber, M., M. R. Scheeder, P. Ossent, C. Lischer, and H. Geyer. 2006. The content and composition of lipids in the digital cushion of the bovine claw with respect to age and location - A preliminary report. Vet. J. 172:173-177.

Rainwater-Lovett, K., J. M. Pacheco, C. Packer, and L. L. Rodriguez. 2009. Detection of foot-and-mouth disease virus infected cattle using infrared thermography. Vet. J. 180:317-324.

Schaefer, A. L., N. J. Cook, C. Bench, J. B. Chabot, J. Colyn, T. Liu, E. K. Okine, M. Stewart, and J. R. Webster. 2012. The noninvasive and automated detection of bovine respiratory disease onset in receiver calves using infrared thermography. Res. Vet. Sci. 93:928-935.

Schaefer, A. L., N. J. Cook, J. S. Church, J. Basarab, B. Perry, C. Miller, and A. K. Tong. 2007. The use of infrared thermography as an early indicator of bovine respiratory disease complex in calves. Res. Vet. Sci. 83:376-384.

Smith, B. I., J. Kauffold, and L. Sherman. 2010. Serum haptoglobin concentrations in dairy cattle with lameness due to claw disorders. Vet. J. 186:162-165.

Sprecher, D. J., D. E. Hosteler, and J. B. Kaneene. 1997. A lameness scoring system that uses posture and gait to predict dairy cattle reproductive performance. Theriogenology 47:1179-1187.

Stokes, J. E., K. A. Leach, D. C. Main, and H. R. Whay. 2012. An investigation into the use of infrared thermography (IRT) as a rapid diagnostic tool for foot lesions in dairy cattle. Vet. J. 193:674-678.

Strabel, D., A. Ewy, T. Kaufmann, A. Steiner, and M. Kirchhofer. 2007. Rumenocentesis: A suitable technique for analysis of rumen juice pH in cattle? Schweiz. Arch. Tierheilkd. 149:301-306.

Toussaint Raven, E. 1989. Cattle Foot Care and Claw Trimming. Farming Press, Ipswich, UK.

Whay, H. R., D. C. Main, L. E. Green, and A. J. Webster. 2003. Assessment of the welfare of dairy cattle using animal-based measurements: Direct observations and investigation of farm records. Vet. Rec. 153:197-202.

Wilhem, K., J. Wilhem, and M. Fuerll. 2012. Subclinical laminitis in dairy cattle - Thermographic examination of the claw and relations to energy metabolism. Page 75 in Proc. 27th World Buiatrics Congress, Lisbon, Portugal. Revista Portugesa da Buitria, Lisbon, Portugal. 